\title{
Lanreotide Long-Acting Aqueous Gel
}

National Cancer Institute

\section{Source}

National Cancer Institute. Lanreotide Long-Acting Aqueous Gel. NCI Thesaurus. Code C65111.

A long-acting aqueous gel preparation of lanreotide, a synthetic cyclic octapeptide analogue of somatostatin. Lanreotide inhibits the secretion of growth hormone $(\mathrm{GH})$ by binding to pituitary somatostatin receptors, and may inhibit the release of various other hormones, including thyroid stimulating hormone (TSH) and the gastroenteropancreatic hormones insulin, glucagon and gastrin. This agent also decreases circulating total and free insulin-like growth factor 1 (IGF-I). Lanreotide exhibits a high binding affinity for somatostatin receptor 2 (SSTR-2) and a lesser binding affinity for SSTR-5. However, compared to octreotide, this agent is less potent in inhibiting the release of growth hormone from the pituitary gland. 